Universidade Tecnológica Federal do Paraná - UTFPR Campus Ponta Grossa - Paraná - Brasil

ISSN: 1981-3686/ v. 08, n. 02 suplemento: p. 1488-1500, 2014

D.O.I. $10.3895 / \mathrm{S} 1981-36862014000200004 \mathrm{~S} 1$
Revista Brasileira de Tecnologia

Agroindustrial

\title{
UTILIZAÇÃO DE RESÍDUO DO PROCESSAMENTO DE ACEROLA (Malpighia emarginata D.C.) NA CONFECÇÃO DE BISCOITO TIPO LÍNGUA DE GATO
}

\section{UTILIZATION OF ACEROLA PROCESSING WASTE (Malpighia emarginata D.C.) IN MAKING BISCUIT TYPE OF CAT TONGUE}

\author{
Paula Cristina Carvalho Lima ${ }^{1}$; Roniel Geraldo Avila ${ }^{2}$; Debora Valim da Silva ${ }^{3}$; Polyana Faria Cardoso \\ Marília Daniela de Oliveira ${ }^{5}$ \\ ${ }^{1}$ Universidade Federal de Viçosa - UFV - Viçosa - Brasil paulinhahlima@yahoo.com.br \\ 2,3,4,5 Instituto Federal de Educação, Ciência e Tecnologia do Sul de Minas Gerais - IFSMG - Muzambinho - \\ Brasil
}

\begin{abstract}
Resumo
Os resíduos originados do processamento de frutas contêm muitos nutrientes. Considerando os altos índices de desperdício de alimentos e o considerável valor nutricional, merece destaque a secagem de resíduos para obtenção de farinha como ingrediente alimentar rico em fibras para incorporação nos mais diversos alimentos em substituição parcial à farinha de trigo, portanto o presente trabalho teve por objetivo avaliar a aplicação tecnológica da farinha de resíduo do processamento da acerola (Malpighia emarginata D.C.) na confecção de biscoitos tipo língua de gato. Estes foram elaborados substituindo-se $20 \%$ da farinha de trigo e avaliados quanto às características centesimais: umidade, resíduo mineral ou fração de cinzas, proteína bruta, extrato etéreo, fibra bruta, carboidratos e valor calórico, além das análises microbiológicas (coliformes, $\underline{\text { Staphylococcus }} \underline{s p}$. e Salmonella $s p$.$) . O teste de aceitabilidade foi realizado através de escala$ hedônica 9 pontos. Os biscoitos adicionados de farinha de resíduo de acerola apresentaram boas quantidades de lipídeos, proteínas, matéria mineral e carboidratos, e, quando comparados aos biscoitos confeccionados sem o resíduo, apresentaram maiores teores de fibras e menor valor calórico. A aceitabilidade foi muito boa, apresentando médias sensoriais positivas para os atributos sabor, textura e aroma. De maneira geral, observou-se que a inserção de farinhas de resíduos ricas em fibras alimentares, pode melhorar a qualidade nutricional dos biscoitos sem comprometer suas características sensoriais, além de apresentar-se menos calóricos e oferecer uma alternativa para o aproveitamento do resíduo de maneira econômica e nutritiva.
\end{abstract}

Palavras-chave: subprodutos; fibra alimentar; biscoitos.

\section{Introdução}

A indústria de alimentos produz grande volume de resíduos resultantes da produção, preparo e consumo de alimentos. A utilização e o destino apropriado destes resíduos vêm se tornando uma preocupação nos últimos anos (MORETTI e MACHADO, 2006). Segundo Abud e Narain (2009), além do desperdício e combate à desnutrição, há a crescente preocupação com o descarte destes 
resíduos, que podem levar a problemas ambientais pela presença de substâncias de alto valor orgânico, potenciais fontes de nutrientes para microrganismos, como também a perdas de biomassa e energia, exigindo investimentos significativos em tratamentos para controlar a poluição.

Inúmeros estudos utilizando resíduos industriais do processamento de alimentos têm sido realizados visando a redução do impacto ambiental e o desenvolvimento de tecnologias que agreguem valor aos produtos obtidos (KOBORI e JORGE, 2005; LAUFENBERG et al., 2003; PELIZER et al., 2007). A aplicação tecnológica de subprodutos na indústria alimentícia além de reduzir consideravelmente o resíduo desperdiçado, trazendo impacto positivo para economia, também contribuiria na produção de alimentos saudáveis (GIUNTINI et al., 2003).

$\mathrm{Na}$ indústria de alimentos, o termo "resíduos" é utilizado para descrever uma parte da matéria-prima não utilizada ou rejeitada durante o processamento do produto principal. No caso de indústrias de polpa de fruta, os resíduos referem-se ao "bagaço" (resíduos de frutos) obtidos durante o processamento de extração de polpa de frutas. O mercado de polpas de frutas congeladas disparou nas últimas décadas, decorrente dos novos hábitos alimentares e, está sendo considerado um grande potencial (BORGES, 1999).

O Brasil é um país com alto potencial para a produção de frutas tropicais, de alto valor nutricional, presença de vitaminas e pigmentos naturais, e com grandes possibilidades de industrialização (OLIVEIRA et al, 2005), sendo considerado um dos maiores produtores de frutas do mundo, porém com índices de desperdício desses produtos ao redor de 30 a $40 \%$ (COSTA et al., 2007).

O aumento no consumo de polpa de fruta gera uma maior produção de bagaço, que é o resíduo de frutas industrializadas, composta de pele de frutas, caroços e sementes (MATIAS et al., 2005). Este quadro que temos na agroindústria e também no setor agrícola, apresenta não apenas o problema do impacto ambiental, mas também do desperdício (ABUD e NARAIN, 2009).

Em geral, calcula-se que do total de frutas processadas sejam geradas na produção de sucos e polpas, $40 \%$ de resíduos agroindustriais para as frutas manga, acerola, maracujá e caju. Atualmente, as agroindústrias investem no aumento da capacidade de processamento, gerando grandes quantidades de subprodutos, que em muitos casos são considerados custo operacional para as empresas ou fonte de contaminação ambiental (LOUSADA JÚNIOR et al., 2006).

O Brasil é o maior produtor, consumidor e exportador de acerola (Malpighia emarginata D.C.) no mundo. Considerada como uma das principais fontes naturais de ácido ascórbico (Vitamina C), a acerola, nos últimos anos, tem sido bastante estudada no sentido de se aproveitar ao máximo esse componente, frente a curta vida útil da fruta in natura e ao seu baixo índice de 
processamento (CARVALHO, 2000; GOMES et al., 2002). Além disso, a acerola apresenta um grande potencial de aproveitamento industrial, o que tem despertado o interesse dos produtores, passando a ter importância econômica em várias regiões do Brasil (NOGUEIRA et al., 2002; FREITAS et al., 2006).

Como o homem necessita, de qualquer modo, de uma alimentação sadia, rica em nutrientes, isto pode ser alcançado com partes de alimentos que normalmente são desprezadas. Sendo assim, é importante a utilização de cascas de frutas e hortaliças, pois o aproveitamento integral dos alimentos, além de diminuir os gastos com alimentação e melhorar a qualidade nutricional do cardápio, reduz o desperdício de alimentos e torna possível a criação de novas receitas (GONDIM et al., 2005).

Inúmeros estudos utilizando resíduos industriais do processamento de alimentos têm sido realizados visando a redução do impacto ambiental e o desenvolvimento de tecnologias que agreguem valor aos produtos obtidos (KOBORI e JORGE, 2005; LAUFENBERG et al., 2003; PELIZER, et al, 2007). Dentre as tecnologias empregadas, merece destaque a secagem de resíduos para obtenção de farinha como ingrediente alimentar rico em fibras para incorporação nos mais diversos alimentos, em substituição parcial à farinha de trigo (ABUD et al., 1994; MATIAS et al., 2005).

Diante do exposto, o presente trabalho teve por objetivo estudar o aproveitamento de resíduos do processamento da acerola a partir da farinha do resíduo desidratado na incorporação de biscoito tipo língua de gato e sua aceitabilidade entre consumidores, como forma de fornecer um destino ao resíduo estudado e minimizar o desperdício.

\section{Material e Métodos}

Foram utilizados frutos de aceroleiras cultivadas no IFSULDEMINAS- Campus Muzambinho, Minas Gerais, próximo ao setor de Mecanização a uma altitude de 1.033 metros, latitude $21^{\circ} 18^{\prime} 00^{\prime}$ 'S e longitude $46^{\circ} 30^{\prime} 00^{\prime}$ 'W. Após a colheita realizada no mês de março de 2013, os frutos de acerola foram levados para o laboratório de Bromatologia e Água do IFSULDEMINAS, onde foram inicialmente selecionados manualmente com a finalidade de retirar pedaços de galhos, pedúnculos de frutos, folhas e frutos estragados ou inadequados. Depois da seleção, os frutos passaram por uma pré-lavagem com agua potável em abundância para retirada das impurezas macroscópicas e posteriormente sofreram sanitização (200 mg L ${ }^{-1}$ de cloro por 20 minutos) e foram novamente lavados para retirada de resíduos de cloro e realização de seu processamento. 
Realizou-se processamento dos frutos em liquidificador modelo RI2008 - Philips / Walita e separação do resíduo com Peneira caseira de Nylon (12 cm de diâmetro), posteriormente o resíduo foi disposto em bandeja de inox e desidratado em estufa de secagem com circulação de ar (modelo Solab SL 100) a uma temperatura de $60^{\circ} \mathrm{C}$ por cerca de 6 horas, depois do processo de desidratação, o resíduo obtido foi levado para o centro de produção da panificadora Canaã em Muzambinho, Minas Gerais, onde foi disposto em assadeira de alumínio com dimensões 35 x 35 x $6 \mathrm{~cm}$ e torrado em forno industrial a uma temperatura de $160^{\circ} \mathrm{C}$ por cerca de 15 minutos. Após esse processo, os resíduos foram moídos em liquidificador modelo RI2008 - Philips / Walita, para a obtenção de uma farinha mais grossa, que posteriormente foi armazenada em recipientes plásticos herméticos transparentes em polipropileno e mantidos à temperatura ambiente, para posterior processamento dos biscoitos.

O processo de confecção foi manual para os biscoitos padrão e adicionados de resíduo de processamento da acerola e as receitas foram desenvolvidas conforme a tabela 1.

Tabela 1 - Formulação dos biscoitos

\begin{tabular}{c|c|c}
\hline Ingredientes & $\begin{array}{c}\text { Padrão* } \\
\mathbf{0 \%}\end{array}$ & $\begin{array}{c}\text { Biscoito Tipo I ** } \\
\mathbf{2 0 \%}\end{array}$ \\
\hline Farinha do Resíduo da acerola & $0 \mathrm{~g}$ & $25 \mathrm{~g}$ \\
Farinha de Trigo & $125 \mathrm{~g}$ & $100 \mathrm{~g}$ \\
Açúcar & $40 \mathrm{~g}$ & $40 \mathrm{~g}$ \\
Clara de Ovo & $35 \mathrm{~g}$ & $35 \mathrm{~g}$ \\
Manteiga & $40 \mathrm{~g}$ & $40 \mathrm{~g}$ \\
Essência de Baunilha & $320 \mathrm{~g}$ & $320 \mathrm{~g}$ \\
\hline
\end{tabular}

* Padrão= biscoito confeccionado sem o resíduo, **Biscoito Tipo I= biscoito confeccionado com o resíduo.

O processo produtivo foi realizado da seguinte forma: em uma batedeira misturou-se a manteiga com o açúcar, batendo a uma velocidade alta até obter um creme homogêneo, após esse processo juntou-se a clara de ovo com a essência de baunilha e, sempre batendo, incorporou-se delicadamente a farinha de trigo juntamente com a farinha de resíduo até formar uma massa firme e homogênea. Após a obtenção da massa houve a distribuição dos biscoitos em formato de círculos em uma assadeira de alumínio com dimensões $35 \times 35 \times 6 \mathrm{~cm}$ e posterior cocção em forno a uma temperatura alta (cerca de $280{ }^{\circ} \mathrm{C}$ ), onde os biscoitos foram retirados do forno quando as bordas apresentavam-se coradas (cerca de 7 minutos).

A avaliação centesimal foi realizada no laboratório de Bromatologia e Água do IFSULDEMINAS, onde os métodos utilizados para as avaliações foram: umidade, com o emprego 
do calor em estufa ventilada à temperatura de $105^{\circ} \mathrm{C}$, com verificações esporádicas até obtenção de peso constante (AOAC, 1990); fibra bruta pelo método gravimétrico após a hidrólise ácida, (KAMER e GINKEL, 1952); proteína bruta, determinada do teor de nitrogênio por destilação em aparelho de Microkjedahl (AOAC, 1990); extrato etéreo (lipídios) usando o aparelho de extração contínua tipo Soxhlet (AOAC, 1990); resíduo mineral ou fração cinzas determinado gravimetricamente avaliando a perda de peso do material submetido ao aquecimento a $550{ }^{\circ} \mathrm{C}$ em mufla (AOAC, 1990); fração glicídica (carboidratos) determinada através do cálculo: \% F.G. = 100 - $(\mathrm{U}+\mathrm{EE}+\mathrm{P}+\mathrm{F}+\mathrm{C})$, sendo FG = Fração Glicídica (\%); U = Umidade (\%); EE = Extrato etéreo (\%); P = Proteína (\%); F = Fibra Bruta (\%) e C = Cinzas (\%), considerando a matéria integral; valor calórico usando os fatores de conversão de Atwater: $4 \mathrm{Kcal} / \mathrm{g}$ para proteínas, $4 \mathrm{Kcal} / \mathrm{g}$ para carboidratos e $9 \mathrm{kcal} / \mathrm{g}$ para lipídios, conforme Osborne \& Voogt (1978); quantidade de coliformes, Staphylococcus sp. e Salmonella sp. (SILVA et al., 2001).

$\mathrm{Na}$ análise sensorial foram utilizados 97 avaliadores não treinados, que analisaram de forma monádica o quanto gostaram ou desgostaram do biscoito, utilizando escala hedônica estruturada de nove pontos (gosto extremamente, gosto muito, gosto moderadamente, gosto ligeiramente, não gosto e nem desgosto, desgosto ligeiramente, desgosto moderadamente, desgosto muito e desgosto extremamente) para os atributos: aroma, textura e sabor, conforme (DUTCOSKY, 2007).

\section{Resultados e Discussão}

No teste de aceitabilidade foram oferecidas amostras do produto (Figura 1) para provadores não treinados, observou-se que o biscoito obteve uma boa aceitação que pode ser evidenciada com os dados de preferência pelo sabor, textura e aroma.

Figura 1 - Apresentação do produto final
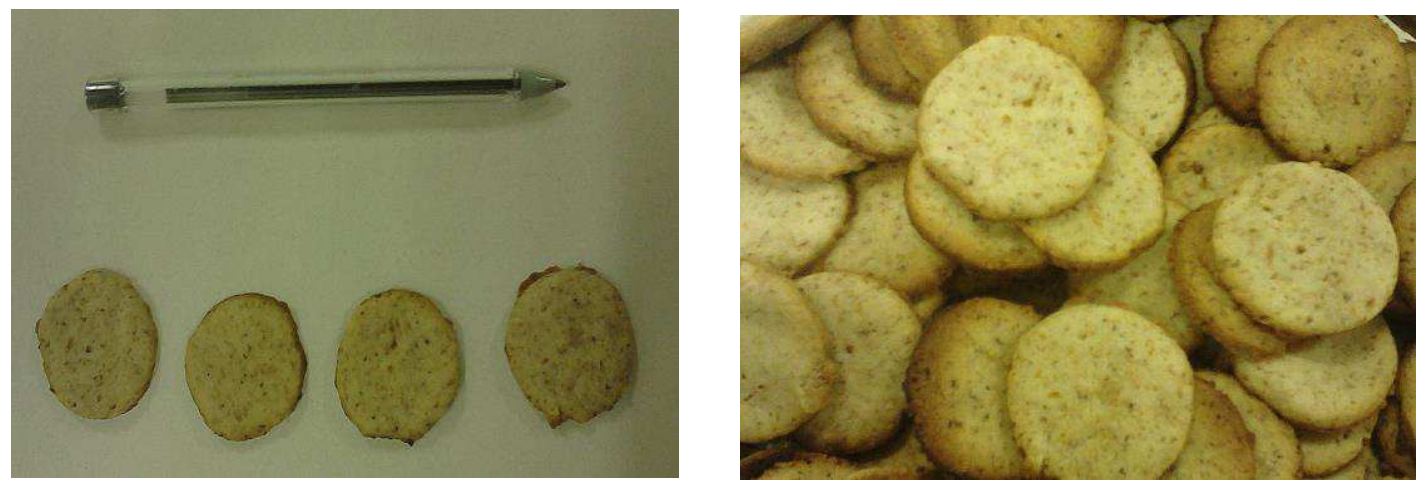

FONTE: Arquivo pessoal, 2013. 
Do total de provadores (97 avaliadores), 64\% eram do sexo feminino e $36 \%$ do sexo masculino e a faixa etária dos provadores foi de 15 a 60 anos, sendo que $82,47 \%$ encontravam-se entre 15 e 30 anos, $11,34 \%$ encontravam-se entre 30 e 45 anos e $6,19 \%$ de 45 a 60 anos.

Em relação ao Sabor de uma maneira geral 30,92\% disseram gostar extremamente, $44,33 \%$ disseram gostar muito, $15,46 \%$ disseram gostar moderadamente, 7,23\% disseram gostar ligeiramente, $1,03 \%$ não gostaram nem desgostaram e apenas $1,03 \%$ disseram que desgostaram muito do sabor do biscoito (Figura 2). Observou-se um escore médio de 7,91, maior que o encontrado por Aquino et al. (2010), que ao caracterizar biscoitos tipo cookie adicionados de $20 \%$ de farinha de resíduo de acerola obtiveram um escore médio de 3,56 para o parâmetro Sabor.

Ainda na figura 2, quando se relaciona separadamente a avaliação do sabor ao sexo do provador, observa-se boa aceitabilidade para ambos os sexos, onde as avaliações relacionadas aos provadores do sexo feminino apresentaram porcentagens de $33,87 \%$ e $45,16 \%$ para os escores 9 e 8 (gostei extremamente e gostei muito, respectivamente) e nas avaliações dos provadores do sexo masculino foram observadas porcentagens de $25,71 \%$ e $42,85 \%$ para os escores 9 e 8 (gostei extremamente e gostei muito respectivamente).

Quando se relaciona separadamente a avaliação do sabor a faixa etária dos provadores (Figura 2), também é possível observar boa aceitabilidade, principalmente na faixa etária que compreende provadores entre 15 e 30 anos $(82,47 \%)$, onde na avaliação relacionada a essa faixa etária se observou porcentagens de $30 \%$ e $48,75 \%$ para os escores 9 e 8 (gostei extremamente e gostei muito, respectivamente).

Figura 2 - Sabor do biscoito confeccionado com resíduo do processamento de acerola em relação ao sexo (A) e faixa etária (B)

A

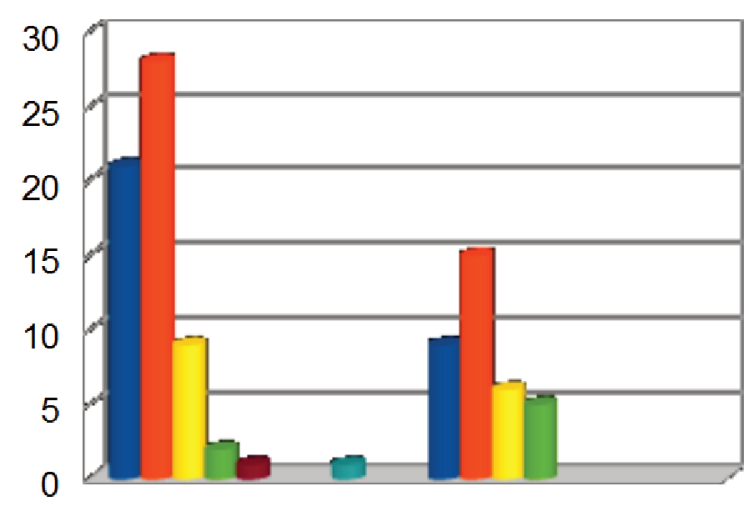

Feminino
Masculino
B

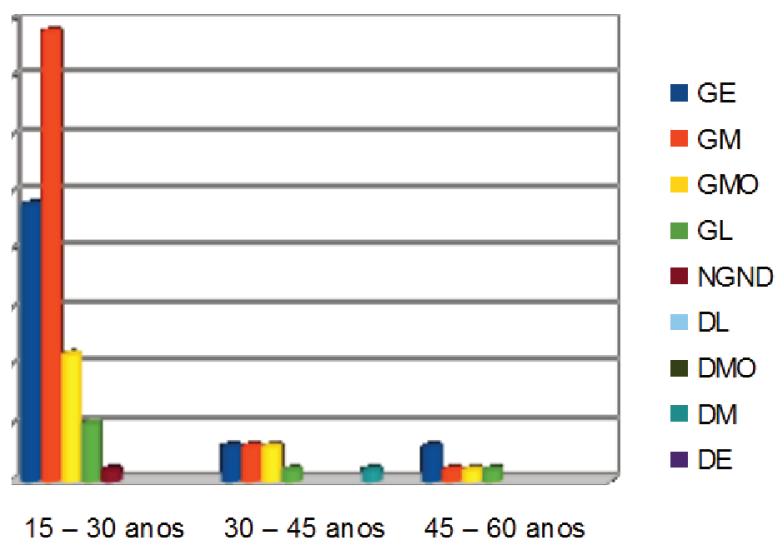

$15-30$ anos $30-45$ anos $45-60$ anos

$\mathrm{GE}=$ gosto extremamente, $\mathrm{GM}=$ gosto muito, $\mathrm{GMO}=$ gosto moderadamente, $\mathrm{GL}=$ gosto ligeiramente, $\mathrm{NGND}=$ não gosto e nem desgosto, $\mathrm{DL}=$ desgosto ligeiramente, $\mathrm{DMO}=$ desgosto moderadamente, 
Em relação à textura 19,02\% disseram gostar extremamente, 34,02\% disseram gostar muito, $22,68 \%$ disseram gostar moderadamente, $15,46 \%$ disseram gostar ligeiramente, $2,07 \%$ não gostaram nem desgostaram, 2,07\% desgostaram moderadamente e 4,12\% disseram que desgostaram ligeiramente da textura do biscoito confeccionado com o resíduo de acerola (Figura 3). Observouse um escore médio de 7,32, que se apresenta maior que o encontrado por Aquino et al. (2010), que ao caracterizar biscoitos tipo cookie adicionados de $20 \%$ de farinha de resíduo de acerola obtiveram um escore médio de 4,18 para o parâmetro Textura.

Ainda na figura 3, quando se relaciona separadamente a avaliação da textura ao sexo do provador, observa-se uma maior aceitabilidade relacionada as avaliações dos provadores do sexo feminino, que apresentaram porcentagens de $20,92 \%, 40,32 \%$ e $16,12 \%$ para os escores 9,8 e 7 (gostei extremamente, gostei muito e gostei moderadamente, respectivamente), quanto as avaliações dos provadores do sexo masculino foram observadas porcentagens de $17,14 \%, 22,85 \%$ e $34,26 \%$ para para os escores 9, 8 e 7 (gostei extremamente, gostei muito e gostei moderadamente, respectivamente).

Quando se relaciona separadamente a avaliação da textura a faixa etária dos provadores (Figura 3), também é possível observar boa aceitabilidade, principalmente na faixa etária que compreende provadores entre 15 e 30 anos $(82,47 \%)$, onde na avaliação relacionada a essa faixa etária se observou porcentagens de 18,75\%,33,75\% e 22,50\% para os escores 9, 8 e 7 (gostei extremamente, gostei muito e gostei moderadamente, respectivamente).

Figura 3 - Textura do biscoito confeccionado com resíduo do processamento de acerola em relação ao sexo (A) e faixa etária (B).
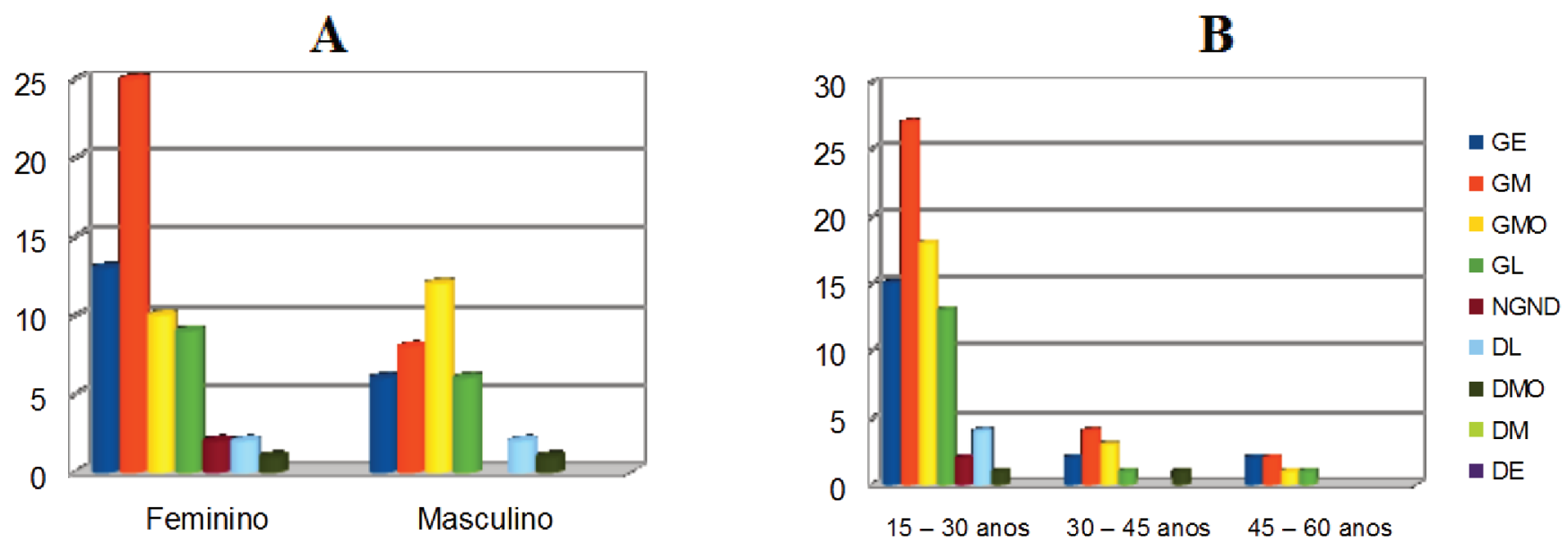

\footnotetext{
$\mathrm{GE}=$ gosto extremamente, $\mathrm{GM}=$ gosto muito, $\mathrm{GMO}=$ gosto moderadamente, $\mathrm{GL}=$ gosto ligeiramente, NGND= năo gosto e nem desgosto, $\mathrm{DL}=$ desgosto ligeiramente, $\mathrm{DMO}=$ desgosto moderadamente, $\mathrm{DM}=$ desgosto muito $\mathrm{DE}=$ desgosto extremamente.
} 
Em relação ao aroma 19,59\% disseram gostar extremamente, 51,55\% disseram gostar muito, $14,43 \%$ disseram gostar moderadamente, $13,40 \%$ disseram gostar ligeiramente e apenas 1,03\% não gostaram nem desgostaram do aroma do biscoito (Figura 4). Observou-se um escore médio de 7,75, que se apresenta maior que o encontrado por Aquino et al. (2010), que ao caracterizar biscoitos tipo cookie adicionados de $20 \%$ de farinha de resíduo de acerola obtiveram um escore médio de 4,16 para o parâmetro Aroma.

Ainda na figura 4, quando se relaciona separadamente a avaliação do aroma ao sexo do provador, observa-se uma maior aceitabilidade relacionada as avaliações dos provadores do sexo feminino, que apresentaram porcentagens de $20,96 \%, 53,22 \%$ e $11,29 \%$ para os escores 9,8 e 7 (gostei extremamente, gostei muito e gostei moderadamente, respectivamente), quanto as avaliações dos provadores do sexo masculino foram observadas porcentagens de $17,14 \%, 48,57 \%$ e $20 \%$ para para os escores 9, 8 e 7 (gostei extremamente, gostei muito e gostei moderadamente, respectivamente).

Quando se relaciona separadamente a avaliação do aroma a faixa etária dos provadores (Figura 4), também é possível observar boa aceitabilidade, principalmente na faixa etária que compreende provadores entre 15 e 30 anos $(82,47 \%)$, onde na avaliação relacionada a essa faixa etária se observou porcentagens de 16,25\%, 52,50\% e 13,75\% para os escores 9, 8 e 7 (gostei extremamente, gostei muito e gostei moderadamente, respectivamente).

Figura 4 - Aroma do biscoito confeccionado com resíduo do processamento de acerola em relação ao sexo (A) e faixa etária $(B)$.

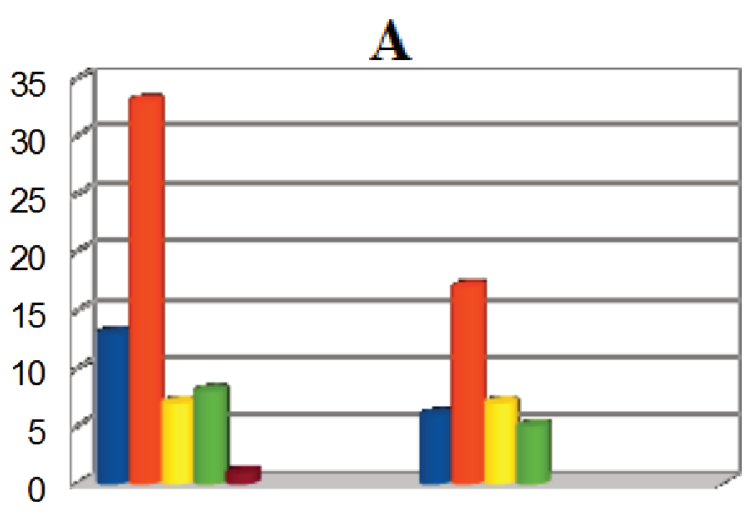

Feminino
Masculino
B

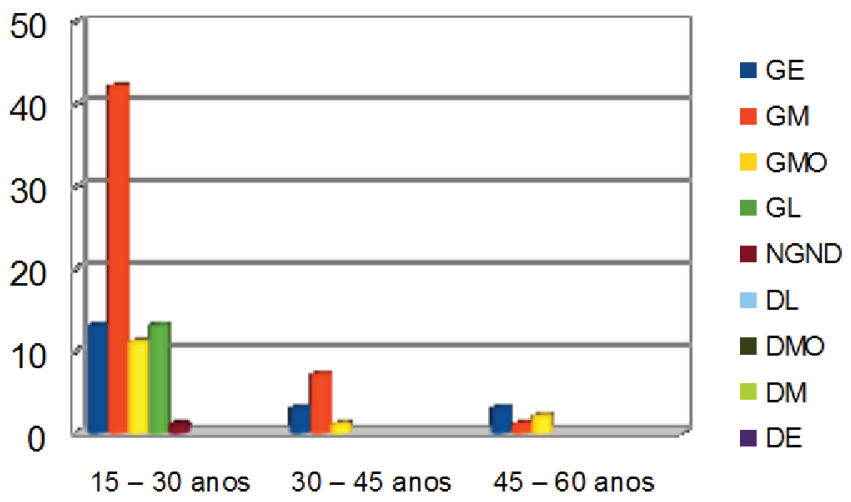


Tais resultados demonstram que os biscoitos formulados substituindo-se a farinha de trigo por $20 \%$ da farinha de de resíduo do processamento da acerola pode vir a ser viável comercialmente, pois apresentaram boa aceitabilidade por grupos distintos, necessitando de estudos mais aprofundados a respeito. De acordo com Santucci et al. (2003), a mistura de farinhas de produtos não convencionais com a farinha de trigo melhora a qualidade nutricional de biscoitos e pode até melhorar sua palatabilidade tornando-o mais aceito pelos consumidores. E por ser um produto de baixo custo, pode facilmente ser consumido pelas classes sociais menos privilegiadas.

Os resultados das análises centesimais são apresentados na Tabela 2. Observou-se que o biscoito confeccionado com o resíduo do processamento da acerola apresentou boas quantidades de lipídeos, proteínas, matéria mineral e carboidratos, e quando comparado com o biscoito confeccionado sem o resíduo apresentou maiores teores de fibras e menor valor calórico. Apresentando também menor valor calórico quando comparado com biscoito tipo 'amanteigado', que fornece $625 \mathrm{Kcal} 100 \mathrm{~g}^{-1}$ (DERMA LINE, 2013).

Tabela 2 - Composição centesimal da matéria-prima, biscoito confeccionado com o resíduo e biscoito controle em $100 \mathrm{~g}$ de amostra.

\begin{tabular}{|c|c|c|c|}
\hline Parâmetros Físico-Químicos & FRDA* & Padrão** & Biscoito Tipo I*** \\
\hline Umidade (g.100g $\left.{ }^{-1}\right)$ & $12,6 \pm 0,08$ & $0,7 \pm 0,02$ & $1,4 \pm 0,06$ \\
\hline Cinzas $\left(\mathrm{g} .100 \mathrm{~g}^{-1}\right)$ & $1,4 \pm 0,07$ & $0,7 \pm 0,02$ & $0,7 \pm 0,03$ \\
\hline Proteína Bruta $\left(\mathrm{g} .100 \mathrm{~g}^{-1}\right)$ & $6,4 \pm 0,12$ & $9,7 \pm 0,12$ & $9,8 \pm 0,06$ \\
\hline Extrato Etéreo $\left(\mathrm{g} .100 \mathrm{~g}^{-1}\right)$ & $2,9 \pm 0,06$ & $17,8 \pm 0,01$ & $17,1 \pm 0,01$ \\
\hline Fibra Bruta $\left(\mathrm{g} .100 \mathrm{~g}^{-1}\right)$ & $45,7 \pm 5,60$ & $17,4 \pm 0,51$ & $20,2 \pm 1,64$ \\
\hline Carboidratos $\left(\mathrm{g.100g}^{-1}\right)$ & $30,9 \pm 5,52$ & $53,7 \pm 0,63$ & $50,7 \pm 1,69$ \\
\hline Calorias (Kcal) & $175,5 \pm 22,13$ & $413,4 \pm 2,08$ & $396,2 \pm 6,44$ \\
\hline
\end{tabular}

Média de duplicata \pm desvio padrão

*FRDA = farinha do resíduo do despolpamento de acerola; **Padrão= biscoito confeccionado sem o resíduo de acerola; ***Biscoito Tipo I= biscoito confeccionado com o resíduo de acerola.

Ainda na Tabela 2, em comparação com os resultados obtidos na literatura para a farinha de resíduo de acerola, observou-se que foi obtido um maior teor de umidade que os encontrados por Aquino et al. (2010) e Abud e Narain (2009) (8,60 e 7,02 g.100 g ${ }^{-1}$, respectivamente), porém um menor teor de cinzas, cerca de 1,40 g. $100 \mathrm{~g}^{-1}$, quando comparados com os valores encontrados pelos mesmos autores $\left(3,03 \mathrm{e} 2,13 \mathrm{~g} .100 \mathrm{~g}^{-1}\right.$, respectivamente). 
Em relação ao biscoito tipo língua de gato confeccionado com os resíduos de acerola (Tabela 2), os teores de cinzas $\left(0,75 \mathrm{~g} \cdot 100 \mathrm{~g}^{-1}\right)$ estavam de acordo com a legislação brasileira de alimentos e bebidas, cujo teor máximo de cinzas permitido em biscoitos é 4,0\% (BRASIL, 1978), porém estão abaixo do que os encontrados por Aquino et al. (2010), que ao caracterizar biscoitos tipo cookie confeccionados com a substituição de $10 \%$ da farinha de trigo pela farinha de resíduos de acerola, encontraram cerca de $1,88 \mathrm{~g} \cdot 100 \mathrm{~g}^{-1}$ de teores de cinzas.

$\mathrm{Na}$ tabela 2, o resíduo desidratado da acerola apresentou teor proteico de $6,45 \mathrm{~g} .100 \mathrm{~g}^{-1}$ menor que os encontrados por Aquino et al. (2010) e Abud e Narain (2009), que ao caracterizarem a farinha dos resíduos da acerola, encontraram um teor proteico equivalente a 8,88 e 7,02 g. $100 \mathrm{~g}^{-1}$, respectivamente. Por sua vez, Lousada Junior et al., (2006) obtiveram valor de 10,5 g. $100 \mathrm{~g}^{-1}$ para o farelo de acerola desidratado. O biscoito tipo língua de gato confeccionado com o resíduo de acerola apresentou teor proteico de 9,85 g. $100 \mathrm{~g}^{-1}$, maiores que os $6,78 \mathrm{~g} .100 \mathrm{~g}^{-1}$ encontrados por Aquino et al. (2010), para biscoitos tipo cookie confeccionado com o resíduo de acerola.

A análise de lipídeos da farinha em estudo (Tabela 2), indicou maior teor de lipídeos $(2,87$ g. $100 \mathrm{~g}^{-1}$ ) em relação ao teor de $0,52 \mathrm{~g} \cdot 100 \mathrm{~g}^{-1}$ obtido por Aquino et al. (2010) e menor quando comparado com o teor de 5,23 g. $100 \mathrm{~g}^{-1}$ encontrado por Abud e Narain (2009). Já os biscoitos tipo língua de gato confeccionados com o resíduo de acerola apresentaram cerca de 17,09 g.100g ${ }^{-1}$ de teor de lipídeos, valor maior que os 10,40 g.100 ${ }^{-1}$ encontrados por Aquino et al. (2010).

Em relação aos teores de fibra bruta, o biscoito tipo língua de gato confeccionado com o resíduo de acerola apresentou cerca de 20,17 g. $100 \mathrm{~g}^{-1}$ (Tabela 2), maior que os 17,37 g.100g ${ }^{-1}$ encontrado para o biscoito padrão, provavelmente devido à grande quantidade de fibra bruta apresentada pela farinha de resíduo de acerola $\left(45,70 \mathrm{~g} .100 \mathrm{~g}^{-1}\right)$, que no presente estudo foi utilizada substituindo $20 \%$ da farinha de trigo na confecção de biscoito tipo língua de gato. Tais teores também são mais elevados do que os encontrados por Protzek et al. (1998), que elaboraram biscoitos com diferentes níveis de substituição da farinha de trigo por farinha de bagaço de maçã e encontraram valores de fibra alimentar total de 2,70 a $6,05 \mathrm{~g} .100 \mathrm{~g}^{-1}$ nos biscoitos.

Sendo assim, a substituição parcial da farinha de trigo representa uma boa alternativa de aproveitamento do resíduo de acerola, uma vez que consumo de fibras alimentares está associado com resultados benéficos para o organismo humano e mesmo para a prevenção de algumas doenças crônicas (BELLO, 1995), além de que, dentre as tecnologias empregadas, merece destaque a secagem de resíduos para obtenção de farinha como ingrediente alimentar rico em fibras para incorporação nos mais diversos alimentos, em substituição parcial à farinha de trigo (ABUD et al.,1994; MATIAS et al., 2005). 
Quanto às análises microbiológicas, os biscoitos confeccionados com o resíduo de acerola apresentaram total ausência de qualquer microrganismo (coliformes, Staphylococcus sp. e Salmonella sp.) que pudesse a vir causar algum tipo de contaminação, estando assim, dentro das características microbiológicas aceitáveis para o consumo humano.

\title{
4 Conclusões
}

O aproveitamento do resíduo do processamento de acerola na alimentação humana apresenta-se como uma boa alternativa, pois o biscoito confeccionado com este resíduo contém boas quantidades de matéria mineral, proteína bruta, lipídeos, valor calórico e maior teor de fibras comparado ao biscoito confeccionado sem o resíduo. A introdução do resíduo do processamento de acerola na confecção de biscoito do tipo língua de gato apresentou boa aceitabilidade, demonstrando que a inserção de farinhas de resíduos ricas em fibras, pode melhorar a qualidade nutricional dos biscoitos sem comprometer suas características sensoriais, além de apresentar-se menos calóricos e oferecer uma alternativa para o aproveitamento do resíduo de maneira econômica e nutritiva.

\begin{abstract}
The waste generated from processing fruits contain many nutrients. Considering the high levels of food waste and considerable nutritional value, deserves drying waste to obtain flour as a food ingredient rich in fibers for incorporation in various foods partial replacement of wheat flour, so the present study was evaluate the technological application of flour acerola processing waste (Malpighia emarginata DC) in the making of biscuit type cat tongue. These were prepared by replacing $20 \%$ wheat flour and evaluated for proximate characteristics: moisture content, mineral residue or fraction of ash, crude protein, ether extract, crude fiber, carbohydrate and calorie content, and microbiological analysis (coliforms, Staphylococcus $\underline{s p}$. and Salmonella sp.). The acceptability test was performed using a hedonic scale of 9 points. The biscuits added flour acerola residue had good amounts of lipids, proteins, carbohydrates and mineral matter, and when compared with the biscuit made without the residue showed higher fiber content and lower calorie content. The acceptability was very good, with average positive sensory attributes for flavor, texture and aroma. In general, it was observed that the insertion of flour residue rich in dietary fiber, can improve the nutritional quality of biscuits without compromising their sensory characteristics, and present themselves less calories and offer an alternative to the use of waste in a manner economical and nutritious.
\end{abstract}

Key-words: by-products; dietary fiber; biscuits.

\section{Referências}

ABUD, A. K. S.; SANTOS, M. N.; SILVA, R. P. Obtenção da Farinha da Semente da Jaca: Estudo de sua Viabilidade em Substituição à Farinha de Trigo. In: CONGRESSO BRASILEIRO DE FRUTICULTURA, 13, 1994, Salvador. Anais... Jaboticabal: Sociedade Brasileira de Fruticultura, v. 3, p. 1069 -1069, 1994. 
ABUD, A. K. S; NARAIN, N. Incorporação do resíduo de processamento de polpa de frutas em biscoito: uma alternativa de combate ao desperdício. Brazilian Journal Food Technology, v. 12, n. 4, p. 257-265, 2009. http://dx.doi.org/10.4260/BJFT2009800900020.

AQUinO, A. C. M. S.; MÓES, R. S.; LEÃO, K. M. M; FIGUEIREDO, A. V. D.; CASTRO A. A. Avaliação físicoquímica e aceitação sensorial de biscoitos tipo cookies elaborados com farinha de resíduos de acerola. Revista Instituto Adolfo Lutz, v. 69, n. 3, p. 379-86, 2010.

A.O.A.C. (Association of Official Agricultural Chemists). Official Methods of the Association of the Agricultural Chemists. 15.ed., v.2., Washington, 1990.

BELLO, J. Los alimentos funcionales nutraceuticos: funciones saludables de algunos componentes de los alimentos. Alimentaria, n. 267, 1995, p. 49-58.

BORGES, S.; MARTINS, K. A.; SILVA, M. S. Utilização dos frutos de jatobá-do-cerrado (Hymenaea stigonnacarpa mrt.) e jatobá-da-mata ( Hymenaea stilbocarpa mart.) na elaboração de biscoitos com reduzido teor de açucares e alto teor de Fibra alimentar. Ciência e Tecnologia de Alimentos, v. 19, p.21-30, 1999.

BRASIL. Ministério da Saúde. Resolução CNNPA n. 12, de março de 1978. Aprova o regulamento técnico para biscoitos e bolachas. Diário Oficial da União, Brasília, DF, 24 jul. 1978. Seção 1, p.11499.

CARvalho, R. A. Análise econômica da produção de acerola no município de Tomé-Açú, Pará. Belém: Embrapa Amazônia Oriental, 2000. 21p.

COSTA, J. M. C; FELIPE, E. M. F.; MAIA, G. A.; BRASIL, I. M.; HERNANDEZ, F. F. H. Comparação dos parâmetros fisico-químicos de pós alimentícios obtidos de resíduos de abacaxi. Revista Ciência Agronômica, v. 38, n. 2, p. 228-32, 2007.

DERMA LINE. Tabela Calórica. Disponível em: <http://www.dermaline.com.br/Tabela-Calorica.aspx>. Acesso em: 08 março 2013.

DUTCOSKY, S. D. Análise Sensorial de Alimentos. 2ª ed. Curitiba, Paraná: Universitária Champagnat, 2007.

FREITAS, C. A. S.; MAIA, G. A.; COSTA, J. M. C.; FIGUEIREDO, R. W.; SOUSA, P. H. M. Acerola: produção, composição, aspectos nutricionais e produtos. Revista Brasileira de Agrociência, v. 12, n. 4, p. 395-400, 2006.

GIUNTINI, E. B., LAJOLO, F. M., MENEZES, E. W. Potencial de fibra alimentar em países ibero-americanos: alimentos, produtos e resíduos. Archivos Latinoamericanos de Nutrición, v. 53, n. 1, p. 14-20, 2003.

GOMES, P. M. A.; FIGUEIREDO, R. M. F.; QUEIROZ, A. J. M. Caracterização e isotermas de adsorção de umidade da polpa de acerola em pó. Revista Brasileira de Produção Agroindustrial. v. 4, n. 2, p.157-65, 2002.

GONDIM, J. A. M.; MOURA, M. F.; DANTAS, A. S.; SANTOS, K. M. Composição centesimal e de minerais em cascas de frutas. Revista Ciência e Tecnologia de Alimentos, v.25, n.4, p. 825-827, 2005. http://dx.doi.org/10.1590/S0101-20612005000400032

KAMER, J. H. V.; GINKEL, L. Rapid determition of crude fiber in cereais. Cereal Chemistry, Saint Paul, v. 29, n. 4, p. 239-251, 1952.

KOBORI, C. N.; JORGE, N. Caracterização dos óleos de algumas sementes de frutas como aproveitamento de resíduos industriais. Revista Ciência e Agrotecnologia, v. 29, n. 5, p. 1008-1014, 2005.

LAUFENBERG, G.; KUNZ, B.; NYSTROEM, M. Transformation of vegetable waste into value added products: (a) the upgrading concept; (b) pratical implementations. Bioresource Technology, v. 87, n. 2, p. 167-198, 2003.

LOUSADA JÚNIOR, J. E.; COSTA, J. M. C.; NEIVA, J. N. M.; RODRIGUEZ, N. M. Caracterização físico-química de subprodutos obtidos do processamento de frutas tropicais visando seu aproveitamento na alimentação animal. Revista Ciência Agronômica, v. 37, n. 1, p. 70 -76, 2006. 
MATIAS, M. F. O.; OLIVEIRA, E. L.; MARGALHÃES, M. M. A., GERTRUDES, E. Use of fibers obtained from the cashew (Anacardium ocidentale L.) and guava (Psidium guayava) fruits for enrichment of food products. Brazilian Archives of Biology and Technology, v. 48, n. Especial, p. 143-150, 2005. http://dx.doi.org/10.1590/S151689132005000400018

MORETTI, C. M.; MACHADO, C. M. M. Aproveitamento de resíduos sólidos do processamento mínimo de frutas e hortaliças. 4, 2006, São Pedro. In: ENCONTRO NACIONAL SOBRE PROCESSAMENTO MÍNIMO DE FRUTAS E HORTALIÇAS. Palestras, Resumo, Fluxogramas e Oficinas... Piracicaba: USP/ESALQ, p. 25-32, 2006.

NOGUEIRA, R. J. M. C.; MORAES, J. A. P. V.; BURITY, H. A; SILVA JUNIOR, J. F. Efeito do estádio de maturação dos frutos nas características físico-químicas de acerola. Pesquisa Agropecuária Brasileira, v.37, n.4, p.463-470, 2002. http://dx.doi.org/10.1590/S0100-204X2002000400006

OLIVEIRA, A.; SILVA, M. G. F. ; SOBRAL, P. J. A. ; OLIVEIRA, C. A. F. ; HABITANTE, A. M. Q. B. Propriedades físicas de misturas para sherbets de mangaba. Pesquisa Agropecuária Brasileira, v. 40, n. 06, p. 581-586, 2005. http://dx.doi.org/10.1590/S0100-204X2005000600008

OSBORNE, D. R.; VOOGT, P. The analysis of nutrient in foods. London: Academic, 1978.

PELIZER, L. H.; PONTIRRI, M. H., MORAES, I. O. Utilização de resíduos agro-industriais em processos biotecnológicos como perspectiva de redução do impacto ambiental. Journal of Technology Management e Innovation, v. 2, n. 1, p. 118-127, 2007.

PROTZEK, E. C.; FREITAS, R. J. S.; WASCZYNSKJ, N. Aproveitamento do bagaço de maça na elaboração de biscoitos ricos em fibra alimentar. Boletim CEPPA, v. 16, n. 2, p. 263-275, 1998.

SANTUCCI, M. C.C., ALVIM, I.D., FARIA, E.V., SGARBIERI, V.C. Efeito do enriquecimento de biscoitos tipo água e sal com extrato de levedura (Saccharomyces sp.). Revista Ciência e Tecnologia de Alimentos, v. 23, n. 3, p. 441-6, 2003.

SILVA, N.; JUNQUEIRA, V. C. A.; SILVEIRA, N. F. A. Manual de métodos de análise microbiológica de alimentos. 2 ed. Livraria Varela. São Paulo, 2001, 229p.

Submetido em 20 mai. 2013, Aceito para publicação em 26 jun. 2014, Publicado em 28 dez. 2014. 